\title{
Os determinantes do preço das terras agrícolas na história do pensamento econômico *
}

\author{
Tiago Santos Telles * \\ Bastiaan Philip Reydon ${ }^{* * *}$ \\ Vitor Bukvar Fernandes ${ }^{* * * * *}$
}

\begin{abstract}
Resumo
As investigações sobre os determinantes dos preços das terras agrícolas, bem como a análise do mercado de terras, são temas recorrentes na história do pensamento econômico. Nesse sentido, o objetivo deste estudo é investigar os conceitos sobre esses determinantes e, de forma mais específica, sistematizar o pensamento econômico sobre o mercado de terras. Para tanto são resgatados os traços distintivos das escolas pré-clássica, clássica, marxista e neoclássica. Além disso, são apresentados os argumentos teóricos sobre o "paradoxo do preço da terra" e a relação da nova economia institucional com a determinação dos preços da terra. Por fim, comenta-se a contribuição de cada escola do pensamento econômico para a construção do debate teórico acerca do mercado de terras agrícolas.
\end{abstract}

Palavras-chave: Valor da terra; Renda da terra; Economia agrícola; Teoria econômica; Preço da terra.

Abstract

\section{Farmland price determinants in the history of economic thought}

The research on the determinants of farmland prices, as well as land market analysis, are recurrent topics in the history of economic thought. In this respect, the aim of this study is to research the concepts of these determinants and, more specifically, to systemize the economic thinking about land markets. For this purpose, distinctive features of classical, Marxist and neoclassical schools of economics were recovered. The work provides the theoretical arguments about the "land price paradox" and complements them with the new institutional economics view on the determinants of farmland prices. Finally, comments are made about the contribution of the theoretical debate about land markets.

Keywords: Land value; Land rent; Agricultural economics; Economic theory; Land prices. JEL B00, N5, Q00.

\section{Introdução}

Na literatura econômica há inúmeras hipóteses sobre quais são os fatores determinantes dos preços das terras. A relevância do mercado de terras na dinâmica econômica capitalista é demonstrada pela profusa literatura sobre o tema, que remete aos primórdios daquilo que hoje se considera a moderna ciência econômica. Entre

\footnotetext{
${ }^{*}$ Artigo recebido em 1 de novembro de 2016 e aprovado em 30 de janeiro de 2017.

** Pesquisador do Instituto Agronômico do Paraná (Iapar), Londrina, PR, Brasil. E-mail: telles@iapar.br.

*** Professor Titular do Instituto de Economia da Universidade Estadual de Campinas (Unicamp, IE), Campinas, SP, Brasil. E-mail: bastiaan@unicamp.br.

${ }^{* * * *}$ Doutor em Desenvolvimento Econômico pela Universidade Estadual de Campinas (Unicamp, IE), Campinas, SP, Brasil. E-mail: vitorbukvar@gmail.com.
} 
as inúmeras questões suscitadas sobre o mercado de terras ao longo da história do pensamento econômico, o modo pelo qual o preço da terra é determinado constitui um dos principais objetos de estudo da área.

Desde os séculos XVIII e XIX, pensadores da economia davam grande atenção à "terra". A discussão originária sobre essa temática se dá no contexto histórico da revolução industrial e, em particular, das revoluções burguesas europeias, considerado por Moreira (1995) um período de transição. Para o autor, este período histórico está associado à absolutização da propriedade da terra e sua transformação em mercadoria, livre de entraves ${ }^{1}$ - mercado de terras.

A origem dos estudos acerca da terra remete à economia pré-clássica, ou seja, ao início dos escritos mercantilistas do século XVII, não como categoria principal, mas procurando estabelecer relações do valor da terra com a taxa de juros - sendo a renda da terra um dos principais fluxos monetários da época. Para os mercantilistas, mesmo com toda sua direção voltada ao comércio como bem básico de produção, a terra não era considerada mercadoria ${ }^{2}$. Esse mesmo mercantilismo, diferentemente do mercado auto regulável, defendia a intervenção do Estado na economia. Havia grande preocupação com o desenvolvimento do país em relação aos seus recursos naturais. Para eles, as formas de integração e suas estruturas institucionais de suporte seriam dependentes das relações sociais, da divisão do trabalho, das relações de propriedade, da separação entre consumidores e produtores e da forma de atuação do Estado. Elas constituiriam sistemas de troca e distribuição dos elementos materiais necessários à satisfação das necessidades humanas. As terras agrícolas seriam, então, uma fonte de riqueza.

Ainda na concepção pré-clássica, os fisiocratas surgem partindo da oposição à redução da riqueza para o dinheiro e às políticas protecionistas defendidas pelos mercantilistas. Os fisiocratas desenvolveram a ideia de ordem natural, na qual as sociedades humanas estavam sujeitas a leis da natureza, tendo a terra um papel especial neste processo ${ }^{3}$. Na esfera econômica, o direito natural das pessoas era desfrutar dos frutos do seu trabalho, desde que isso fosse coerente e respeitasse o direito do outro. Os governos somente deveriam proteger a vida e a propriedade,

(1) Segundo Smith (1990), trata-se de um processo social e político que envolve a ruptura da estrutura hierárquica, circunscrita à propriedade feudal. As trajetórias constitutivas dos Estados absolutistas evidenciam, histórica e assincronicamente, a centralização do poder do rei e a desvinculação da propriedade de seus traços feudais, abrindo-lhe a possibilidade de adquirir forma mercantil, livre de quaisquer outros atributos que não os da condição de mercadoria.

(2) Para Polanyi (1957): "Mercantilism, with all its tendency toward commercialization, never attacked the safeguards which protected these two basic elements of production -labor and land-from becoming the objects of commerce".

(3) Cantillon (2010 [1775]), em sua obra Essai sur la Nature du Commerce en Général, considera a os valores intrínsecos das mercadorias como redutíveis a quantidades de terra direta e indiretamente necessária para produzi-las ao propor que o valor do trabalho pode ser medido pela quantidade de alimento necessária para reproduzir um trabalhador. 
mantendo a liberdade de contrato. Eles acreditavam que a indústria, o comércio e as profissões eram úteis, mas estéreis, porque simplesmente reproduziam o valor consumido na forma de matérias-primas e subsistência dos trabalhadores. Somente a agricultura era produtiva. Para os fisiocratas, a agricultura gerava um excedente que ia para os proprietários de terra e somente estes deveriam pagar impostos. Estes pensadores atribuem à própria natureza, à fertilidade natural da terra, o poder de gerar um produto líquido (só a natureza fecunda a matéria: as sementes lançadas à terra). Nesse plano, o trabalho produtivo é aquele que produz um excedente, característica que só se verifica no trabalho desenvolvido na agricultura, não por força de qualquer característica específica que distinga o trabalho agrícola do trabalho desenvolvido em outras atividades, mas em virtude de só ele poder aproveitar esse "dom da natureza". Assim sendo, as terras, bem como o seu valor, também eram vistas como fonte de riqueza.

Na economia política clássica e marxista, o debate sobre o "mercado de terras" ganha, progressivamente, notoriedade, desenvolvendo os principais conceitos sobre os determinantes dos preços das terras agrícolas. O mesmo não ocorre na escola neoclássica, que relega o tema a um segundo plano.

Desse modo, o objetivo deste estudo é investigar os conceitos sobre os determinantes dos preços das terras agrícolas e, de forma mais específica, sistematizar o pensamento econômico sobre o mercado de terras.

Para tanto, na seção 1 são apresentados os principais elementos da economia política clássica para o entendimento do mercado de terras; na seção 2 um breve apanhado da visão marxista sobre o tema; na seção 3 um pouco da abordagem neoclássica sobre os determinantes dos preços das terras; na seção 4 o debate sobre o paradoxo do preço das terras agrícolas; na seção 5 a contribuição da nova economia institucional na análise dos determinantes dos preços das terras agrícolas. Por fim, são tecidas as considerações finais.

\section{0 mercado de terras no pensamento clássico}

O debate da economia política clássica sobre os determinantes do valor ou preço das terras agrícolas esteve fortemente atrelado ao que se denominou de year's purchase. Tal expressão indicava que o valor das terras seria determinado a uma taxa anual de capitalização de sua renda, uma vez que se tratava de uma relação de compra e venda em termos de dinheiro ou do fluxo de rendimentos da produção (Mcculloch, 1825). Assim, a terra teria seu preço atrelado à renda auferida pelo proprietário em um determinado período de tempo, ou seja, quanto mais cara a terra maior seria o tempo, em relação aos ganhos de produção (rendimentos), para sua capitalização, sendo que o tempo para o pagamento da terra poderia sofrer alterações em função de oscilações nos preços dos produtos agrícolas comercializados. Nesse sentido, é 
mister dizer que o preço possui uma correspondência com o fluxo de rendimentos capitalizados com a produção agrícola, ou seja, com a renda da terra.

Para Smith (1996 [1776]), o desenvolvimento das sociedades passa, obrigatoriamente, pela renda da terra. Ele considera que toda melhoria da situação da sociedade tende, direta ou indiretamente, a elevar a renda real da terra, a aumentar a riqueza real do proprietário da terra, seu poder de comprar trabalho, ou a produção do trabalho de outras pessoas. A expansão das melhorias e do cultivo da terra tende a elevar a renda da terra de maneira direta. A parcela do proprietário da terra, no processo produtivo, necessariamente aumenta com o crescimento da produção. $\mathrm{O}$ autor esclarece que o aperfeiçoamento das forças produtivas tende a reduzir o custo de produção das mercadorias e, dessa maneira, indiretamente, aumentar a renda da terra. Explica ainda que o contrário também pode ocorrer, ou seja, a estagnação das forças produtivas acarretaria na redução da renda da terra e, consequentemente, de seu preço. Em sua teoria, a produção anual total da terra e do trabalho de cada país, naturalmente, dividir-se-ia em três partes: a renda da terra, os salários da mão-deobra e o lucro do capital. Para ele, os interesses dos proprietários de terra estão diretamente ligados aos interesses das duas outras categorias da sociedade evoluída, ou seja, seria a única das três categorias cuja renda não lhes custa nem trabalho nem cuidado, pois esta renda lhes vem, por assim dizer, espontaneamente, independentemente de qualquer plano ou projeto. A renda da terra seria um excedente do qual o proprietário de terras se apropriaria por meio do exercício do seu poder de monopólio. Para o autor, salários, lucros e a renda da terra fazem parte obrigatoriamente do preço dos produtos. Tais considerações levam à ideia de que esta renda, em geral, seria, então, um preço determinado pelos custos de produção dos seus componentes. Salários, lucro e a renda da terra em si seriam então as três fontes originais de todas as receitas, bem como, de todo o valor de troca. Em síntese, o preço da terra seria determinado pela renda auferida a partir do seu uso ${ }^{4}$, que por sua vez estaria relacionada à sua capacidade produtiva e aos custos de produção.

Malthus (1996 [1798]) partiu do pressuposto de que os recursos naturais, como o solo, são limitados e, se as condições de produção de bens agropecuários se mantivessem constantes, a população tenderia a se multiplicar ao ponto em que não haveria alimentos suficientes para atender a todos. Desta forma, enquanto a produção de alimentos cresceria em progressão aritmética, a população cresceria em progressão geométrica - e dada a condição do solo de recurso limitado, isto implicaria em elevação do preço dos produtos agrícolas. Para ele, a renda da terra seria uma parcela da receita, ou seja, poderia ser definida como a parcela de valor do produto total que sobra para o proprietário da terra após o pagamento de todos os

(4) Vale destacar que seu valor não pode ser determinado diretamente pelos custos de produção, uma vez que a terra não é um bem que possa ser produzido pelo homem. 
custos de produção, de qualquer tipo que seja, incluindo os lucros do capital empregado, estimado de acordo com a taxa de lucros sobre o capital agrícola usual no período considerado. $\mathrm{O}$ alto preço dos produtos agrícolas, poderia ser explicado por três elementos: a qualidade da terra em si - sendo a terra um fator de produção superior por produzir um excedente -; o caráter peculiar de seu produto, que cria a sua própria demanda e força uma expansão desta última; e, a escassez relativa das terras mais férteis. $\mathrm{O}$ autor considera que, com o crescimento da força de trabalho (população ocupada como mão-de-obra), um maior volume de alimentos só poderia ser produzido ao cultivar terras menos férteis ou aplicando capital e trabalho às terras já sob cultivo - com retornos decrescentes. Assim, ao se reduzir os gastos com a produção, terras menos férteis ou mais distantes dos mercados, embora inicialmente não gerando renda, ao longo do tempo cobririam integralmente os custos de produção. E, novamente, quando os lucros do capital ou os salários do trabalho, ou ambos, tiverem caído mais ainda, terras ainda menos férteis, ou menos favoravelmente localizadas, poderão ser cultivadas. E, a cada etapa adicional, fica claro que, se o preço do alimento não diminui, a renda da terra aumentará. Em conclusão, percebe-se que para esse autor havia uma renda diferencial da terra relacionada às expectativas de produção e à sua localização.

Ricardo (1996 [1817]) introduziu algumas modificações no modelo malthusiano. Concordou com Malthus em que havia um limite para a quantidade da terra e uma variabilidade em relação a sua qualidade, assim como concordava com a lei dos retornos decrescentes. Segundo sua teoria, as melhores terras seriam usadas em primeiro lugar, passando-se a terras piores quando necessário. Em consequência, o custo da produção subiria demasiadamente antes que o limite máximo das terras aráveis tivesse sido alcançado. $\mathrm{O}$ ponto em que os custos começariam a subir, bem como a velocidade dessa subida, dependeriam da qualidade das terras disponíveis e do aumento da população, isto é, da demanda. Na teoria ricardiana o exame da renda da terra leva a efeito uma preocupação maior com o comportamento da taxa de lucro, sobretudo com as suas relações com o salário. Para este autor, com a expansão da demanda de produtos agrícolas, devido ao crescimento relativo das atividades não agrícolas no conjunto do sistema econômico, seria necessário cultivar cada vez mais terras de pior qualidade, com maiores custos. Isto levaria a uma crescente elevação real dos preços dos produtos agrícolas e a uma consequente redução na taxa de lucro da economia em geral. Ricardo concretiza a mudança de sentido em relação aos fisiocratas principalmente ao desenvolver sua teoria do valor do trabalho onde a renda é explicada inteiramente em termos do trabalho ${ }^{5}$. De acordo com Blaug (1997), um dos temas centrais da economia ricardiana foi a noção de que o

(5) O que torna a renda da terra também produzida em termos de valor do trabalho e, neste sentido, a fertilidade da terra se torna uma forte ligação entre o valor e o preço das terras agrícolas. 
crescimento econômico chegaria a um impasse devido à escassez dos recursos naturais.

Assim, Smith, Ricardo e Malthus, acreditavam que o principal determinante do valor das terras era a renda que se poderia auferir a partir das atividades produtivas. Mas os clássicos acrescentaram outros pontos no que diz respeito à possibilidade de maior ou menor rendimento com o uso produtivo da terra, que refletiam sobre o seu valor, tais como: localização das unidades produtivas em relação aos centros consumidores e a diferença de "qualidade" entre as terras agrícolas, sobretudo no que diz respeito à sua fertilidade. A possibilidade de avanços tecnológicos foi reconhecida por esses autores, mas eles, de modo geral, acreditavam que esses avanços não poderiam resolver o problema da escassez dos recursos naturais.

Uma série de novas ideias sobre o preço das terras agrícolas foi introduzida por Mill (1996 [1848]). O autor partiu da teoria ricardiana, tendo em conta os usos competitivos da terra e a aplicação do conceito de renda da produção. Ele percebeu que havia terras de melhor qualidade, com solos mais férteis, áreas melhor localizadas, com modelo de produção e de gestão dos negócios, por parte dos agricultores mais competitivos. Para ele, enquanto o proprietário de um novo processo de produção não fosse capaz de suprir todo o mercado, o preço da terra permaneceria no seu valor natural. Assim, a renda da terra nunca entraria no processo de produção como um fator de custo. Mas, se a população continuasse a aumentar, tanto o preço da terra quanto de seus produtos iria subir para um preço que ele considera como de monopólio ou de escassez. O autor enfatizou os dois fatores primários de produção, terra e trabalho, depois de perceber o fato de que o processo econômico de cada período também depende do estoque de bens. Assim, acrescentou o capital como um fator distintivo da produção. Para ele a terra não era apenas um fator de produção, ele também introduziu sua função de provedora de serviços (utilidade). É interessante notar que, a partir dessa função da terra como provedora de serviços (em especial sua importância para qualidade de vida e pela beleza natural, etc.), a necessidade de manter terras preservadas é seu argumento para uma economia estacionária, dado que um aumento ilimitado da riqueza e da população entraria em conflito com esta provisão de serviços.

Mas, uma das principais contribuições dos clássicos foi o desenvolvimento do conceito de renda diferencial da terra, associada à localização das unidades produtivas - em relação aos centros consumidores - e às diferentes características

(6) A qualidade da terra agrícola está relacionada à sua fertilidade natural. Por exemplo, em solos mais férteis é possível obter uma produção maior do que se atingiria em solos menos férteis, considerando uma mesma porção de terra, com a mesma aplicação de trabalho. Em outras palavras, em função das distintas fertilidades das terras, proprietários daquelas consideradas de melhor qualidade acabam por obter uma renda diferencial - sendo este um elo entre o valor e o preço da terra. 
do solo no que tange sua qualidade (fertilidade, capacidade produtiva) e quantidade. $\mathrm{Ou}$ seja, terras de melhor qualidade e melhor localizadas, quando comparadas àquelas de pior qualidade e mais distantes, irão garantir uma renda diferencial ao seu proprietário.

Uma nova dimensão sobre os determinantes dos preços das terras agrícolas foi apresentada por Von Thünen (2009 [1863]). Considerando as teorias malthusiana e ricardiana, e outras voltadas a diferenças em relação às qualidades das terras, considerou a distância do local onde se dá a produção agrícola, dos respectivos centros consumidores, como um dos pontos centrais de sua teoria. Um de seus principais interesses era verificar se havia uma relação entre o padrão de produção agrícola e os dos polos consumidores. Considerou os determinantes dos preços que os agricultores recebiam por seus produtos, bem como suas rendas e os padrões de uso da terra que acompanham tais preços. Assim, desenvolveu um sistema de círculos concêntricos, em que os produtos volumosos ou perecíveis eram produzidos mais perto da cidade e bens valiosos ou duráveis poderiam ser importados de locais mais distantes. Nos polos consumidores centrais, o preço de um produto similar, como os grãos, seria determinado pelos custos de produção e de transporte das fazendas mais distantes, cujos produtos são necessários para atender a demanda da cidade. O grão deve ser vendido ao mesmo preço, independentemente de sua localização de produção, assim sendo, o preço da terra seria mais elevado nos primeiros anéis concêntricos e diminuiria com a distância. Isso porque o custo de produção se forma a partir da localização da unidade produtiva e o preço dos produtos nos mercados, que em termos de produtos agrícolas são competitivos. Assim, ele chegou, por razões diferentes, a conclusões semelhantes da teoria ricardiana, ou seja, que as diferenças na qualidade do solo e a distância da unidade produtiva dos polos consumidores são determinantes do preço da terra.

Para a maioria dos autores acima, a terra ocupava um papel especial no processo de produção. Assim, as questões ligadas à produtividade e a distribuição das rendas auferidas com o uso da terra receberam grande atenção. Mas aos poucos foi perdendo espaço, sendo vista cada vez mais, apenas como um meio de produção. Para Daly (1968) o declínio da importância da terra teve muito a ver com a morte política da aristocracia rural europeia. Com o desenvolvimento da industrialização, os capitalistas e a mão-de-obra industrial se tornaram as classes dominantes e os economistas passaram a dar maior atenção à indústria. Desenvolvimentos tecnológicos importantes que impulsionaram a Revolução Industrial, contribuíram para mudar a percepção da importância da terra, nomeadamente aos olhos dos economistas britânicos.

Os economistas norte-americanos também apresentaram essa percepção: perda de importância da terra na dinâmica econômica. A escola americana tendeu a negar a lei clássica dos rendimentos decrescentes e a doutrina malthusiana da 
população, uma vez que parecia contradizer os fatos do "novo mundo": abundância de terra, propriedade flexível e direitos de posse da terra, e preços determinados através da competição em mercados (Marshall, 1996 [1890]). Esses fatos influenciaram muito a percepção da forma da função de produção. Maior importância foi atribuída aos bens de capital. Foi enfatizado o protecionismo, argumento utilizado contra a existência de retornos decrescentes nas atividades agrícolas. Além disso, consideravam, uma vez que os solos eram ocupados, uma responsabilidade moral em manter a sua fertilidade por meio de sábias práticas agrícolas, pois caso contrário eles iriam se esgotar. De modo geral, capital e terra eram distintos. O capital era visto como uma forma de trabalho, produzido pelo homem, ao passo que a terra era dada e tinha restrições.

Os economistas clássicos lançaram as bases para a economia moderna. O movimento em direção a uma medida cada vez mais homogênea da produção permitiu uma simples agregação de toda a produção no produto total. Mas, na maior parte de suas análises, a terra manteve o seu papel especial. Como a terra fértil foi considerada limitada em oferta, a maioria dos economistas clássicos acreditavam que a produção agrícola estaria sujeita a retornos decrescentes. Por outro lado, máquinas industriais, apesar de não terem a produtividade independente, poderiam ser replicadas. A função de produção agregada, como conceituado por essa corrente de economistas clássicos, pode ser representada pela equação: $Y=f(L, K, N)$, onde: $Y$ equivale ao produto agregado, $L$ ao trabalho, $K$ ao capital e $N$ a terra. Esta tríade clássica foi desenvolvida a partir do reconhecimento das três categorias de participantes no processo econômico (proprietários de terras, trabalhadores e capitalistas), associada a uma tríade da renda (renda, salário, e os juros).

Os pensadores clássicos da economia política buscaram compreender quais eram os fatores que determinavam a renda da terra, e por consequência o seu preço. De modo geral, para eles o valor das terras seria determinado pelas rendas geradas com as atividades agrícolas. Mas acrescentaram outros pontos no que diz respeito à possibilidade de maior ou menor rendimento com o uso produtivo da terra, que refletiam sobre o seu valor, tais como: localização das unidades produtivas em relação aos centros consumidores e a diferença de "qualidade" entre as terras agrícolas, sobretudo no que diz respeito à sua fertilidade. A possibilidade de avanços tecnológicos foi reconhecida, mas eles, de modo geral, acreditavam que estes não poderiam resolver o problema da escassez dos recursos naturais. Apenas adiaria os seus efeitos.

A abordagem unificadora dos economistas clássicos era a sua análise dos valores incorporados ao produto para determinar seu preço. Apesar de utilidade ${ }^{7}$ ser vista como uma condição prévia para que as mercadorias tenham valor, os

(7) Para os clássicos, a responsável pela diferença entre o valor e o preço. 
economistas clássicos eram guiados por sua orientação para o longo prazo, onde os preços relativos apenas foram determinados por custos de produção. Daí a busca em se determinar uma quantidade de trabalho e/ou capital, para fixar valores e preços. Uma orientação muito diferente foi adotada pela nova escola neoclássica, em sua busca por interdependências entre utilidade e os custos de produção.

\section{A visão Marxista sobre o mercado de terras}

Marx aceitou muitas das opiniões dos economistas clássicos. Sua teoria do valor foi fortemente influenciada pela teoria ricardiana. Para ele, o trabalho seria a única fonte de valor de troca. Para haver produção era imprescindível o trabalho. Assim, o processo de trabalho seria a transformação dos recursos naturais em objetos de utilidade para o homem. Assim, o trabalho seria, em primeiro lugar, um processo em que tanto o homem quanto a natureza participam, e em que o homem de sua própria vontade inicia, regula e controla as reações materiais entre si. Marx busca identificar, em sua análise, os determinantes estruturais do preço da terra, não levando em conta o caráter expectacional associado à sua determinação nem as características da concorrência deste mercado. Assim, o preço da terra se eleva a partir da queda da taxa de juro do conjunto da economia, da elevação do juro do capital aplicado ao solo e da elevação da própria renda da terra (Reydon; Plata, 2006).

Para ele, ao proprietário da terra, a mera propriedade jurídica não gera renda, no entanto lhe confere o poder de impedir a exploração de sua terra, ou seja, não pode aumentar, nem diminuir a quantidade absoluta desse campo de aplicação, mas pode alterar a quantidade existente no mercado.

Segundo Graziano da Silva (1981), esse monopólio da terra na agricultura assume dois aspectos distintos. De um lado, o monopólio de uma determinada terra enquanto objeto de atividade econômica, ou seja, o fato do produtor capitalista estar cultivando um determinado pedaço de solo com certas características de fertilidade, localização e de benfeitorias já incorporadas ao solo. De outro lado, o monopólio da propriedade privada da terra em si mesmo, ou seja, o fato de algumas poucas pessoas se arrogarem o direito a uma parcela do globo terrestre e poderem dispor da mesma como bem entenderem. É exatamente esse duplo aspecto que assume o monopólio da terra na agricultura que permite distinguir dois tipos de renda da terra, a diferencial e a absoluta. A renda diferencial da terra é gerada pelo monopólio da sua utilização, da sua exploração. A renda deriva do fato de que o meio de produção "terra", além de não ser homogêneo, é limitado em sua extensão e relativamente não reprodutível, constituindo sua apropriação privada, portanto, um monopólio inevitável em qualquer sociedade capitalista. Como resultado desse monopólio, o preço de mercado de um produto agrícola qualquer tem que ser determinado em função do preço de produção referente à pior terra cultivada (e necessária para 
satisfazer a demanda global) e não pela "média" (se assim não fosse, os produtores localizados nas terras menos produtivas não conseguiriam obter sequer o lucro médio). A renda diferencial é exatamente esse lucro extraordinário, acima do lucro médio, obtido pelos capitais que operam em condições mais favoráveis de produção. É importante ressaltar que não é a terra em si mesma, pelas suas diferenças de qualidade, a causa da renda diferencial, mas sim o fato de que o trabalho aplicado às terras melhores tende a ser mais produtivo, permitindo com isso a geração de um lucro adicional. A renda diferencial é, portanto, apenas uma conversão desse lucro suplementar à renda. Conversão que se torna possível pela propriedade fundiária, dado que esta habilita seu proprietário a embolsar o sobrelucro, mesmo que tenha sido outro - o arrendatário capitalista - quem tenha extorquido a mais valia aos trabalhadores empregados nessa "terra mais produtiva". A renda diferencial pode, por sua vez, ser decomposta em duas: I) aquela fração "natural", proveniente das diferenças de localização (em relação ao mercado) e de fertilidade inerente aos tipos de solos; e, II) aquela fração "fabricada" pelas inversões suplementares de capital (ou seja, de meios de produção e de trabalho) numa mesma área de terra. A renda diferencial I se refere ao fato de que capitais da mesma grandeza aplicados em terras diferentes produzem resultados desiguais. A renda diferencial II advém do fato de que capitais de mesma grandeza aplicados sucessivamente na mesma terra produzem também resultados diferentes, sendo por isso, considerada como a renda da terra proveniente da intensificação da agricultura pelo capital. Para o autor, é importante deixar claro que a renda diferencial representa sempre uma diferença nos preços de produção em relação ao pior solo cultivado (em termos de localização e fertilidade), de onde se pode concluir que este último tem renda diferencial nula. Seria então gratuita a exploração do mesmo? Evidentemente não, pois em caso contrário o monopólio da terra pela classe de proprietários não teria sentido.

Graziano da Silva (1981) destaca que para Karl Marx a propriedade privada da terra constitui apenas a condição necessária, mas não suficiente para a existência de renda, seja a diferencial, seja a absoluta. Para a existência da renda diferencial seria preciso também que as terras fossem distintas em termos de fertilidade (natural), de localização e de retorno aos investimentos sucessivos de capital (no sentido técnico) nela aplicados. Para a existência da renda absoluta seria necessário, além da propriedade privada da terra que a torna de fato o monopólio de uma classe, que a composição orgânica do capital, na agricultura propriamente dita, fosse inferior à do capital social médio. Em virtude do limite estabelecido pela propriedade fundiária, o preço de mercado subiria até o ponto em que o (pior) solo pagasse um excedente sobre o preço de produção, isto é, uma renda. Uma vez que o valor das mercadorias produzidas pelo capital agrícola supera o preço de produção, essa renda constitui o excedente do valor sobre o preço de produção, ou parte dessa sobra. Assim, se a composição média do capital agrícola fosse igual ou superior à do capital 
social médio, desapareceria a renda absoluta, no sentido considerado - isto é, diferente da renda diferencial e, ainda, daquela (renda) oriunda do preço de monopólio da terra.

\section{0 mercado de terras agrícolas na teoria neoclássica}

Na teoria neoclássica a "terra" perde importância. Para Cohen (1989), isso se deve principalmente à substituição da teoria clássica do valor-trabalho por uma nova concepção de valor, subjetiva, trazida pela teoria marginalista, que passou a ter quase que a hegemonia dentro da teoria econômica vigente a partir de então. Para ele, de modo geral, em conformidade com sua teoria do valor, a utilidade e a escassez dos recursos naturais determinariam o valor e preço para os mesmos, incluída a terra. No caso da utilidade, explicam eles, o valor é derivado do uso previsível do bem ou serviço final em que eles participaram. No caso da escassez, os bens abundantes e ilimitados são bens livres, de preço zero e, aqueles que são relativamente escassos, têm valor e preço. Assim sendo, a terra, por ser um recurso natural útil e escasso, formaria seus preços da mesma forma que os demais bens capital em uma economia. Mas, para eles, assim como para os clássicos, o preço das terras seria determinado, de modo geral, pela relação direta com os retornos econômicos das atividades produtivas.

Para os neoclássicos, de modo geral, a renda da terra - bem como o seu preço - seria determinada seguindo os princípios da teoria da utilidade marginal e, de modo específico, considerando a renda auferida com a comercialização dos produtos extraídos da terra. Segundo Menger (1983 [1871]) a renda da terra seria diretamente proporcional ao valor previsível de sua utilização, mas inversamente proporcional no que diz respeito aos requerimentos de capital para produção agrícola. Uma das principais contribuições dos neoclássicos para o entendimento dos determinantes dos preços das terras foi a renda da escassez de Marshall (1996 [1890]), que se daria em função da quantidade limitada desse fator de produção. Assim, acréscimos da demanda para cada unidade de terra uma vez que a oferta é fixa, gerariam, para equilibrar o mercado, uma elevação dos preços; em uma situação inversa, uma redução da demanda se traduziria em queda nos preços. Para Walras (1996 [1898]) tanto a renda da terra quanto a do trabalho e a do capital, bem como seus preços, em geral, são definidos simultaneamente, havendo um só preço - renda - para cada um dos fatores produtivos, sendo necessário, que estes preços mostrem a eficiência na produção e no consumo.

Nesse sentido, a escola neoclássica busca unificar a explicação da remuneração dos fatores de produção com base nos conceitos de produtividade marginal e de equilíbrio de mercado. No entanto, na teoria keynesiana ${ }^{8}$ há um

(8) Ver Telles et al. (2016). 
posicionamento diferente, uma vez que não necessariamente o equilíbrio significa pleno emprego dos fatores, uma vez que não há como assegurar uma distribuição ótima da renda para todos, sendo preciso estabelecer uma função de bem-estar social como base, para que isso ocorra (Keynes, 1982 [1936]). Segundo Hoffmann (2001), com a dominância neoclássica, grandes temas do desenvolvimento econômico foram relegados a um segundo plano durante as primeiras décadas do século $\mathrm{XX}$, a favor do que hoje se conhece como microeconomia. Esses temas voltaram a ganhar importância após a "revolução" keynesiana na corrente neoclássica.

\section{O paradoxo do preço da terra}

De forma geral, é possível identificar, ao menos até meados da década de 1950, mesmo com vigência da teoria econômica keynesiana, um relativo consenso na literatura - ainda que heterogênea - acerca dos determinantes do preço da terra. Com efeito, as várias correntes teóricas que se debruçaram sobre o mercado de terras, sobretudo a clássica e a neoclássica, consideraram o preço do ativo ali negociado como resultado, direto ou indireto, do fluxo de rendimentos, atual e esperado, que dele se pode auferir (Larsen, 1948; Reydon; Plata, 2006). Em outras palavras, mesmo partindo de pressupostos distintos quanto à operação da economia em geral, e ao papel que a terra nela desempenha, é possível identificar, quanto aos determinantes do preço da terra, um elemento comum nas diversas abordagens teóricas que compõem as investigações sobre o tema: o preço da terra é determinado pelos rendimentos que a mesma pode gerar àquele que dela faz uso. Vale dizer que, em última instância, de acordo com essa perspectiva, o valor da terra é ditado pela sua capacidade produtiva e pelos retornos, atuais e esperados, a ela associada. Assim, o preço da terra seria, simplesmente, o valor presente do fluxo de rendimentos da atividade agrícola.

A década de 1950, contudo, marca um ponto de inflexão em relação a isto. A relativa concordância entre os estudiosos do tema foi abalada a partir desse período, quando diversos estudos empíricos constataram que os preços das terras nos Estados Unidos se elevaram muito acima daquilo que seria justificado pelos rendimentos derivados de sua utilização a contramão, portanto, do que as teorias de então sugeriam (Scofield, 1957; Chryst, 1965). De fato, conforme argumentam Shalit e Schmitz (1982), se, entre 1910 e 1950, os preços das terras norte-americanas se apresentavam fortemente relacionadas à renda que dela se podia extrair, a partir das décadas de 1960 e 1970, os preços das terras se elevaram a despeito do declínio do rendimento derivado da atividade agrícola.

Frente ao que ficou conhecido como "paradoxo do preço da terra" (Chryst, 1965), denominação dada na literatura ao fenômeno acima descrito, inúmeros estudiosos passaram a considerar fatores não estritamente relacionados ao 
rendimento associado à capacidade produtiva da terra como determinantes de seu valor - ainda que vários destes autores tenham restringindo a influência desses outros determinantes ao impacto que tinham no próprio setor agrícola. As pesquisas se voltaram, dessa forma, para o exame de outros fatores, além dos produtivos, que poderiam exercer algum efeito na formação do preço da terra.

A partir de então, o número de análises acerca dos determinantes do preço da terra cresceu prodigiosamente em volume e diversidade - fenômeno não restrito apenas aos Estados Unidos. A inadequação dos modelos de valor presente tradicionais para a precificação da terra fez com que diversas análises passassem a considerar uma ampla e variada gama de fatores na determinação do preço da terra. Além do rendimento associado à produção agrícola, os estudos desde então incorporaram elementos macroeconômicos - tais como a inflação, a taxa de juros -, os programas e políticas governamentais voltados ao setor agropecuário, a pressão exercida pelo processo de urbanização no mercado de terras rurais, entre outros. A percepção de que a terra não é apenas um mero fator de produção, mas um ativo econômico, cujo preço resulta da combinação de fatores vinculados diretamente ao seu uso produtivo e outros elementos, passou a ditar o rumo das pesquisas.

Com efeito, é possível distinguir na literatura três principais conjuntos de variáveis consideradas como determinantes dos preços da terra: (i) medidas das políticas e programas governamentais; (ii) medidas associadas à capacidade produtiva da terra e ao rendimento a ela vinculado; (iii) e, por fim, medidas financeiras e do movimento macroeconômico em geral (Awokuse; Duke, 2006). As análises acerca dos determinantes do preço da terra se diferenciam, sobretudo, quanto à escolha das variáveis representativas de cada um dos três grupos e, também, ao peso, absoluto e relativo, atribuído a cada uma delas na formação do valor da terra - além, evidentemente, das diferentes metodologias utilizadas, como destacadas por Pope et al. (1979), Burt (1986), Varela-Ortega (1986), Capozza e Helsley (1989), Power e Turcy (2010), Sklenicka (2013) e Nickerson e Zhang (2014).

Autores como Alston (1986), Castle e Hoch (1982), Maddison (2000), Huang et al. (2006), Ferro e Castro (2013), Oliveira e Ferreira (2014) e Malassise et al. (2015) estão entre diversos outros que demonstram que o retorno associado à utilização produtiva da terra ainda tem influência significativa na determinação do seu preço. Alston (1986), por exemplo, observou que, de 1963 a 1982, o crescimento real do preço das terras norte-americanas poderia ser explicado de forma robusta pela elevação dos rendimentos delas derivados. Castle e Hoch (1982), por sua vez, argumentaram que, também para os Estados Unidos, cerca de metade das variações dos preços da terra, de 1920 a 1978, derivavam da capitalização do rendimento da atividade agrícola - embora destacassem que a outra parcela possa ser atribuída aos ganhos de capital da terra. Conclusões semelhantes foram apresentadas por Maddison (2000), para o mercado de terras na Inglaterra e no País de Gales, e por 
Huang et al. (2006), para o Estado norte-americano de Illinois entre 1979 e 1999 neste caso, com particular destaque à produtividade da terra.

Por outro lado, autores como Scofield (1957), Chryst (1965), Traill (1979), Reydon e Plata (2006) e Telles et al. (2016) representam um grupo distinto cujo foco da análise se concentra nas variáveis associadas às políticas públicas e ao movimento macroeconômico em geral. Scofield (1957) destacou que o preço da terra possuía uma tendência à valorização a taxa superior à do crescimento da renda gerada por meio de sua utilização produtiva. Para o autor, políticas de sustentação de preços, avanços tecnológicos e até mesmo o uso da terra enquanto reserva de valor - como proteção ao aumento das taxas de inflação, por exemplo - alteram o preço da terra e, por conseguinte, devem ser considerados entre os elementos que a determinam. Chryst (1965), embora defenda que o preço da terra deva refletir o rendimento que dela se é capaz de extrair - sobretudo por aumentos da produtividade -, abre espaço para que sejam também considerados rendimentos não agrícolas na formação do valor da terra. Nessa mesma perspectiva, Traill (1979) verifica que, na Inglaterra, o aumento dos preços das terras nos anos de 1960 foi muito superior aos rendimentos auferidos com as atividades agrícolas, sobretudo em razão das políticas de suporte ao segmento. Ademais, a importância da influência dos programas e políticas governamentais no preço da terra encontra-se bem documentada no conjunto de trabalhos reunidos em Moss e Schmitz (2003), para os Estados Unidos.

Análises mais gerais sobre a determinação do preço da terra foram empreendidas por autores como Tweeten e Martín (1966), Reinsel (1972), Reinsel e Reinsel (1979), Doll et al. (1983), Egler (1985), Just e Miranowski (1993), Weersink et al. (1999), Reydon e Plata (2006), Reydon et al. (2014) e Telles et al. (2016). Reinsel e Reinsel (1979), por exemplo, verificaram que os determinantes dos preços das terras, entre outros, seriam o valor presente do fluxo de rendimentos da terra, o crédito agrícola, a taxa de juros e a taxa de inflação, ou seja, tanto fatores associados às atividades agrícolas quanto aqueles relacionados às políticas públicas direcionadas ao setor e à dinâmica macroeconômica em geral. Na mesma direção, Doll et al. (1983), ao realizar uma avaliação empírica sobre a evolução do preço das terras nos Estados Unidos, elaboraram um modelo que abrangeu tanto variáveis associadas diretamente à atividade agrícola, como a taxa de juros e outras variáveis que refletiam a existência de incentivos governamentais diversos.

De forma geral, verifica-se, portanto, que as políticas públicas direcionadas ao setor agrícola - principalmente as de crédito e de subsídios governamentais - e fatores relativos ao movimento mais geral da economia constituem fatores importantes na determinação dos preços das terras. 


\section{Mercado de terras na corrente institucionalista}

Outra corrente da teoria econômica que trata do mercado de terras é a institucionalista, sendo nominada, por alguns, como new institutional economics". Em meados dos anos 1960, ao revitalizar as ideias de que "instituições importam" 10 , da velha escola institucionalista norte-americana, adicionando o aparato teórico da escola neoclássica, Coase (1998 [1960]) relançou a teoria dos direitos de propriedade no debate das ciências econômicas. A essa discussão é integrada a ideia de custos de transação, fato que deslanchou outra onda de pesquisas na área de direito de propriedade, incluindo o sistema de normas e leis que regulam o uso de determinados recursos naturais, sobretudo a terra (Guedes, Reydon, 2012). North (1990), por sua vez, discute a natureza das instituições como representantes que estabelecem as regras de um jogo em uma sociedade, ou, mais formalmente, como as instrumentalizadoras de restrições concebidas, que moldam o comportamento humano e, por sua vez, podem regular o mercado de terras. Assim, a ponte mais direta para consideração do preço da terra dentro desta corrente seria através das discussões sobre a regulação do direito de propriedade da terra. Para Feder e Feeny (1991), a definição e institucionalização dos direitos de propriedade da terra surgem historicamente em função da continua redução da oferta de terras, ou seja, conforme a terra vai se tornando mais escassa nas sociedades. A natureza destes direitos e a forma como eles são aplicados têm consequências significativas para a alocação de recursos, a eficiência econômica e a regulação dos mercados de terras.

As instituições que regulam o funcionamento dos mercados de terra afetam diretamente os custos de transação associados as relações de compra e venda deste bem (Deininger; Feder, 2001), e estes, por sua vez, podem ser um dos determinantes do preço da terra. Além disso, a insegurança associada ao direito de propriedade em relação à terra, quando não bem definido, pode ser entendida como a probabilidade aleatória da perda de renda futura devido a reivindicações conflitantes. Entretanto, um arranjo com segurança nos direitos de propriedade ${ }^{11}$ não precisa necessariamente se dar através dos direitos de propriedade individualizados (propriedade privada individual da terra). Como os mercados de terras tendem a ser altamente localizados, a facilidade de transferência de terras entre os seus usuários pode ter pouca importância em estágios de baixo desenvolvimento, onde há pouca heterogeneidade da habilidade de cultivar a terra entre a população e as oportunidades não-agrícolas são limitadas. Entretanto, a facilidade de transferência da propriedade dentro de um mercado de terras aumenta drasticamente com o desenvolvimento econômico, especialização e desenvolvimento de outros mercados. Otsuka (2007), sugere que

\footnotetext{
(9) Para maiores detalhes consultar Dugger (1990) e Williamson (2000).

(10) Originalmente nominada institutions matter.

(11) "Tenure security", no original.
} 
mercados de terras com níveis mais elevados e organizados, em relação à transferência de direitos, podem aumentar os investimentos em terras. Já para Hüttel et al. (2016), a partir, principalmente, de políticas públicas - federais, estaduais ou municipais - as instituições podem moldar a formação dos preços das terras e, portanto, a sua alocação, sendo que, em muitas das vezes, estas acabam favorecendo os agricultores locais. No Brasil, um exemplo claro desta questão é a restrição à compra de terras por estrangeiros.

Assim, dado um certo nível de desenvolvimento e população não escassa, para os autores desta corrente a existência de instituições funcionando para garantir um mercado de terras com direitos de propriedade bem estabelecidos traz consigo diversos benefícios: melhor alocação do trabalho agrícola e não agrícola; maior produtividade; desenvolvimento e melhor acesso ao sistema financeiro de crédito utilizando a terra como garantia; diminuição do custo da definição dos direitos de propriedade sobre a terra; transparência e diminuição da assimetria de informação nas transações de terras; facilita o acesso à terra para as camadas de baixa renda; menor custo e maior capacidade de realizar políticas públicas, sejam elas relacionadas à diminuição da desigualdade distributiva de terras, preservação ambiental, aumentar eficiência da taxação, entre tantos outros fatores (Deininger; Feder, 2001).

Deste modo, para os institucionalistas, o direito da propriedade, particularmente em países em desenvolvimento, é um fator importante na determinação do preço das terras agrícolas. Isto porque, intervenções de ordem institucional afetam o preço das terras, pois acabam interferindo nos mecanismos de mercado, que acabam sendo regulados de forma diferente da que seria respeitando o princípio da livre concorrência na ordem econômica.

\section{Considerações finais}

Em busca de avançar na discussão acerca dos determinantes dos preços das terras agrícolas e da dinâmica do mercado de terras, o presente estudo buscou sistematizar o pensamento econômico a respeito dessa questão. Vale destacar que há uma certa complexidade em se estabelecer uma classificação coerente sobre as correntes metodológicas observadas na literatura que tratam das correlações entre o preço e a dinâmica do mercado de terras, ou mesmo uma base linear cronológica de análise. As distintas abordagens acabam se sobrepondo em algum momento do tempo e a única forma de se construir um referencial teórico adequado ao tema é separá-lo em função de seus distintos enfoques.

A partir desta síntese observou-se que parte da literatura econômica sobre o mercado de terras considera os fatores produtivos, relacionados à rentabilidade das atividades agrícolas, como os principais determinantes dos preços das terras, mas 
outra parcela considera que seriam, na verdade, os fatores macroeconômicos, sobretudo associados à especulação, os que mais influenciariam esses preços.

A literatura mostra que parte importante dos estudos sobre o mercado de terras derivam das teorias da economia política clássica, que associam o valor da terra à sua capacidade de gerar renda. Ainda, nesta escola do pensamento econômico foi apresentada a teoria da renda diferencial, formalizada de modo mais abrangente no pensamento ricardiano.

Na visão marxista os preços das terras seriam determinados, sobretudo, pela renda por ela gerada, capitalizada pela taxa de juros da economia. Já a escola neoclássica parte da premissa de que o preço da terra seria determinado pela produtividade marginal do fator, sendo esta a única responsável por sua variação ao longo do tempo.

No entanto, a partir da constatação de que havia uma elevação do preço da terra acima dos ganhos produtivos, o que ficou conhecido como o "paradoxo do preço da terra", outros fatores, além dos produtivos, foram incorporados às investigações acerca dos determinantes dos preços das terras. Houve, então, a necessidade de se buscar referências principalmente nos estudos do mercado financeiro e dos ativos econômicos para explicar a questão do mercado de terras. Uma corrente mais recente que pode contribuir para explicar estes fatores determinantes do preço da terra para além da sua função produtiva é a nova economia institucional, dentro da qual alguns autores se debruçaram na relação entre as instituições e a terra, abrindo espaço para traçar os fatores institucionais que afetam o mercado de terras.

A partir da economia política e da história do pensamento econômico fica claro que os determinantes dos preços das terras agrícolas vão muito além de sua função produtiva. Assim, é possível compreender que em economias dinâmicas, as variáveis macroeconômicas, bem como a conjuntura econômica, e as imbricações das instituições com o mercado de terras, são fatores decisivos para se analisar a formação e determinação dos preços no mercado de terras agrícolas.

\section{Referências bibliográficas}

ALSTON, J. M. An analysis of growth of U.S. farmland prices, 1963-1982. American Journal of Agricultural Economics, v. 68, n. 1, p. 1-9, 1986.

AWOKUSE, T. O.; DUKE, J. M. The causal structure of land price determinants. Canadian Journal of Agricultural Economics, v. 54, n. 2, p. 227-245, 2006.

BLAUG, M. Economic theory in retrospect. Cambridge: Cambridge University Press, 1997. 
Tiago Santos Telles, Bastiaan Philip Reydon, Vitor Bukvar Fernandes

BURT, O. R. Econometric modeling of the capitalization formula for farmland prices. American Journal of Agricultural Economics, v. 68, n. 1, p. 10-26, 1986.

CANTILLON, R. (1755). An essay on economic theory. Auburn: Ludwig von Mises Institute, 2010.

CAPOZZA, D. R.; HELSLEY, R.W. The fundamentals of land prices and urban growth. Journal of Urban Economics, v. 26, n. 3, p. 295-306, 1989.

CASTLE, E. N.; HOCK, I. Farm real estate price components, 1920-1978. American Journal of Agricultural Economics, v. 64, n. 1, p. 8-18, 1982.

CHRYST, W. E. Land values and agricultural income: a paradox? Journal of Farm Economics, v. 47, n. 5, p. 1265-1273, 1965.

COASE, R. The problem of social cost. In: COASE, R. The firm, the market and the law. Chicago: The University of Chicago Press, 1988. p. 95-156.

COHEN, A. J. Prices, capital, and the one-commodity model in neoclassical and classical theories. History of Political Economy, v. 21, n. 2, p. 231-251, 1989.

DALY, H. E. On economics as a life science. Journal of Political Economy, v. 76, n. 3, p. 392-406, 1968.

DEININGER, K; FEDER, G. Land institutions and land markets. In: GARDNER, B. L.; ROUSSER, G.C. (Org.). Handbook of agricultural economics. v. 1: A: Agricultural Production. Amsterdam: North Holland, 2001. p. 287-332. (Handbooks in Economics, n. 18)

DOLL, J. P., WIDDOWS, R.; VELDE, P. D. The value of agriculture land in the United States: a report on research. Agricultural Economics Research, v. 35, n. 2, p. 39-44, 1983.

DUGGER, W. The new institutionalism: New but not institutionalist. Journal of Economic Issues, v. 24, n. 2, p. 423-431, 1990.

EGLER, C. A. Preço da terra, taxa de juro e acumulação financeira no Brasil. Revista de Economia Política, v. 5, n. 1, p. 112-135, 1985.

FEDER, G.; FEENY, D. Land tenure and property rights: Theory and implications for development policy. The World Bank Economic Review, v. 5, n. 1, p. 135-153, 1991.

FERRO, A. B.; CASTRO, E. R. Determinantes dos preços de terras no Brasil: uma análise de região de fronteira agrícola e áreas tradicionais. Revista de Economia e Sociologia Rural, v. 51, n. 3, p. 591-609, 2013.

GRAZIANO DA SILVA, J. Progresso técnico e relações de trabalho na agricultura. São Paulo: Hucitec, 1981. (Economia \& Planejamento). 
GUEDES, S. N. R.; REYDON, B. P. Direitos de propriedade da terra rural no Brasil: uma proposta institucionalista para ampliar a governança fundiária. Revista de Economia e Sociologia Rural, v. 50, n. 3, p. 525-544, 2012.

HOFFMANN, R. Distribuição de renda e crescimento econômico. Estudos Avançados, v. 15, n. 41, p. 67-76, 2001.

HUANG, H.; MILlER, G. Y.; SHERRICK, B. J.; GOMEZ, M. I. Factors influencing Illinois farmland values. American Journal of Agricultural Economics, v. 88, n. 2, p. 458-470, 2006.

HÜTTEL, S.; WILDERMANN, L.; CROONENBROECK, C. How do institutional market players matter in farmland pricing? Land Use Policy, v. 59, p. 154-167, 2016.

JUST, R. E.; MIRANOWSKI, J. A. Understanding farmland price changes. American Journal of Agricultural Economics, v. 75, n. 1, p. 156-168, 1993.

KEYNES, J. M. (1936). A teoria geral do emprego, do juro e da moeda. São Paula: Atlas, 1982.

LARSEN, H.C. Relationship of land values to warranted values, 1910-1948. Journal of Farm Economics, v. 30, n. 3, p. 579-588, 1948.

MADDISON, D. A hedonic analysis of agricultural land prices in England and Wales. European Review of Agriculture Economics, v. 27, n. 4, p. 519-532, 2000.

MALASSISE, R. L. S., PARRÉ, J. L.; FRAGA, G. J. O comportamento do preço da terra agrícola: um modelo de painel de dados espaciais. Revista de Economia e Sociologia Rural, v. 53, n. 4, p. 645-666, 2015.

MALTHUS, T. R. (1798). Princípios de economia política e considerações sobre sua aplicação prática. Ensaio sobre a população. São Paulo: Nova Cultural, 1996. (Os Economistas).

MARSHALL, A. (1890). Princípios de economia. Tratado introdutório, natura non facit saltum. São Paulo: Nova Cultural, 1996. (Os Economistas).

MCCULLOCH, J. R. The principles of political economy: with a sketch of the rise and progress of the science. Edinburgh: William and Charles Tait, Longman, Co. London, 1825.

MENGER, C. (1871). Princípios de economia política. São Paulo: Abril, 1983. (Os Economistas).

MILL, J. S. (1848). Princípios de economia política com algumas de suas aplicações à filosofia social. São Paulo: Nova Cultural, 1996. (Os Economistas).

MOREIRA, R. J. Renda da natureza e territorialização do capital: reinterpretando a renda da terra na competição intercapitalista. Estudos Sociedade e Agricultura, n. 4, p. 89-111, 1995. 
MOSS, C. B.; SCHMITZ, A. Government policy and farmland market. Ames: Iowa State Press, 2003.

NICKERSON, C. J.; ZHANG, W. Modeling the determinants of farmland values in the United States. In: DUKE, J. M.; WU, J. (Ed.). The Oxford Handbook of land economics. New York: Oxford University Press, 2014. p. 111-138.

NORTH, D. C. Institutions, institutional change, and economic performance. New York: Cambridge University Press, 1990.

OLIVEIRA, N.A.P.; FERREIRA, L.R. Determinantes do preço da terra rural no Brasil. Revista de Política Agrícola, v. 23, n. 4, p. 58-75, 2014.

OTSUKA, K. Efficiency and equity effects of land markets. In: EVENSON, R. E.; PINGALI, P. (Org.). Handbook of agricultural economics. v. 3: Agricultural development: farmers, farm production and farm markets. Amsterdam: Elsevier, 2007. p. 287-332. (Handbooks in Economics, 18).

POLANYI, K. The great transformation: The political and economic origins of our time. Boston: Beacon Press, 1957.

POPE, R. D.; KRAMER, R. A.; GREEN, R. D.; GARDNER, B. D. An evaluation of econometric models of U.S. farmland prices. Western Journal of Agricultural Economics, v. 4, n. 1, p. 107-119, 1979.

POWER, G. J.; TURVEY, C. G. US rural land value bubbles. Applied Economics Letters, v. 17, n. 7, p. 649-656, 2010.

REINSEL, R. D. Effect of seller financing on land prices. Agricultural Finance Review, v. 33, p. 32-35, 1972.

REINSEL, R. D.; REINSEL, E. I. The economics of asset values and current income in farming. American Journal of Agricultural Economics, v. 61, n. 5, p. 1093-1097, 1979.

REYDON, B. P.; PLATA, L. E. A. O plano real e o mercado de terras no Brasil: lições para a democratização do acesso à terra. In: REYDON, B. P.; CORNÉLIO, F. N. M. (Org.). Mercados de terras no Brasil: estrutura e dinâmica. Brasília: Nead, 2006. p. 267-284. (Nead Debate, 7).

REYDON, B. P.; PLATA, L. E. A.; SPAROVEK, G.; GOLDSZMIDT, R. G. B.; TELLES, T. S. Determination and forecast of agricultural land prices. Nova Economia, v. 24, n. 2, p. 389-408, 2014.

RICARDO, D. (1817) Princípios de economia política e tributação. São Paulo: Nova Cultural, 1996. (Os Economistas).

SCOFIELD, W. H. Prevailing land market forces. Journal of Farm Economics, v. 39, n. 5, p. 1500-1510, 1957. 
SHALIT, H.; SCHMITZ, A. Farmland accumulation and prices. American Journal of Agricultural Economics, v. 64, n. 4, p. 710-719, 1982.

SKLENICKA, P.; MOLNAROVA, K.; PIXOVA, K. C.; SALEK, M. E. Factors affecting farmland prices in the Czech Republic. Land Use Policy, v. 30, n. 1, p. 130-136, 2013.

SMITH, A. (1776). Investigação sobre a natureza e as causas da riqueza das nações. São Paulo: Nova Cultural, 1996. (Os Economistas).

SMITH, R. Propriedade da terra e transição. São Paulo: Brasiliense, 1990.

SWIERENGA, R. P. Land speculation and frontier tax assessments. Agricultural History, v. 44, n. 3, p. 253-266, 1970.

TELlES, T. S., PALlUDETO, A. W. A.; REYDON, B. P. Price movement in the Brazilian land market (1994-2010): an analysis in the light of post-Keynesian theory. Revista de Economia Política, v. 36, n. 1, p. 109-129, 2016.

TRAILL, B. An empirical model of the U.K. land market and the impact of price policy on land values and rents. European Review of Agricultural Economics, v. 6, n. 2, p. 209-232, 1979.

TWEETEN, L. G.; MARTIN, J. E. A methodology for predicting U.S. farm real estate price variation. Journal of Farm Economics, v. 48, n. 2, p. 378-393, 1966.

VARELA-ORTEGA, C. Una revisión de los modelos sobre el mercado y los precios de la tierra en la literatura económica. Agricultura y Sociedad, n. 41, p. 209-254, 1986.

VON THÜNEN, J. H. (1863). The isolated state in relation to agriculture and political economy. Part III: Principles for the determination of rent, the most advantageous rotation period and the value of stands of varying age in pinewoods. Hampshire: Palgrave Macmillan, 2009.

WALRAS, L. (1898). Compêndio dos elementos de economia política pura. São Paulo: Nova Cultural, 1996. (Os Economistas).

WEERSINK, A.; CLARK, S.; TURVEY, C. G.; SARKER, R. The effect of agricultural policy on farmland values. Land Economics, v. 75, n. 3, p. 425-439, 1999.

WILLIAMSON, O. E. The new institutional economics: taking stock, looking ahead. Journal of Economic Literature, v. 38, n. 3, p. 595-613, 2000. 